\title{
Colposcopy in postmenopausal women: a challenging procedure
}

\author{
Arshdeep Kaur ${ }^{1}$, Gursewak Singh ${ }^{2 *}$
}

\begin{abstract}
${ }^{1}$ Department of Obstetrics and Gynecology, Government Multispeciality Hospital Sector -16, Chandigarh, India ${ }^{2}$ Department of Medicine, Government Medical College Sector-32, Chandigarh, India
\end{abstract}

Received: 26 August 2019

Revised: 30 June 2020

Accepted: 06 July 2020

\author{
*Correspondence: \\ Dr. Gursewak Singh, \\ E-mail: arsh25brar@gmail.com
}

Copyright: () the author(s), publisher and licensee Medip Academy. This is an open-access article distributed under the terms of the Creative Commons Attribution Non-Commercial License, which permits unrestricted non-commercial use, distribution, and reproduction in any medium, provided the original work is properly cited.

\begin{abstract}
Background: Introduction-carcinoma of cervix is the commonest cancer in Indian women. It constitutes $14 \%$ of the total population above age of 50 years. Atrophic changes in the genital tract causes problems in Pap smear as well as in the colposcopy.

Methods: This is prospective observational study conducted in the department of obstetrics and gynecology of SGRDIMSR, Sri Amritsar, which comprised 30 cases of postmenopausal women referred for colposcopy. Inclusion criteria were complaints of post-menopausal bleeding, abnormal vaginal discharge, post coital bleeding, an abnormal PAP smear, an unhealthy-looking cervix. Women with history of any surgery on the cervix in the past three months or with obvious cervical cancer were excluded.

Results: Patient with age group of 44-70 years were included, and maximum number of patients had complaint of post-menopausal bleeding (50\%). 9 (30\%) patients were positive for malignancy on histopathology, while with 9 (30\%) false positive patients on colposcopy. Problems encountered while performing colposcopy includes cervix flushed with vagina, atrophy of introitus, bleeding from the cervix and relaxed vaginal walls. Use of various corrective measures were helpful to overcome the problems of colposcopy.

Conclusions: It is an essential part of cervical screening programme, but it has some limitations and pitfalls which can lead to error in the diagnosis.
\end{abstract}

Keywords: Carcinoma cervix, Colposcopy, Estrogen, Postmenopausal women, Swede’s score

\section{INTRODUCTION}

Carcinoma of cervix is the commonest cancer in Indian women. In India, women aged $>50$ years constitute $14 \%$ of the total population. The atrophic changes in the genital tract cause problems in the Papanicolaou (Pap) smear as well as colposcopy, which are used for screening and confirmation of pre invasive and invasive cervical cancers.

The reasons for colposcopy failing to identify high-grade dysplasia and invasive carcinoma include difficulty with visualising the cervix, inability to visualise the transformation zone, the presence of blood and misinterpretation of the lesions. ${ }^{1,2}$

\section{METHODS}

This was prospective observational study conducted in the department of obstetrics and gynecology of SGRDIMSR, Sri Amritsar, which comprised 30 cases of postmenopausal women referred for colposcopy. The inclusion criteria were complaints of postmenopausal bleeding or abnormal vaginal discharge, post coital bleeding, an abnormal Pap smear, an unhealthy-looking cervix clinically suspicious of malignancy. Women with 
a history of surgery on the cervix in the past three months or with obvious cervical cancer were excluded. A Pap smear was taken with an Ayre's spatula and endocervical brush during speculum examination. Colposcopy was performed at the same visit by the saline technique followed by the classical method, using Leisegang ${ }^{\text {TM }}$ (Germany) stereo-photo colposcope model 3BD at magnifications of $7.5 \mathrm{X}$ and $15 \mathrm{X}$. Colposcopy grading was done on the basis of swede's score. The cervix was swabbed with $3 \%$ acetic acid followed by evaluation of the acetowhite areas with 50\% Lugol's iodine. Abnormal colposcopic appearances were graded and Endocervical curettage (ECC) and cervical and/or vaginal biopsies were performed when indicated. ${ }^{3}$ When there was a diagnostic dilemma, strongly favoring atrophy, oral estrogen therapy was administered for 7-14 days and colposcopy repeated. Estrogen was not administered to women with a Pap smear report of atypical squamous cells, or of doubtful high grade squamous intraepithelial lesion (ASC-H). The procedural and diagnostic problems of colposcopy were noted and the best possible remedies were instituted simultaneously.,5

\section{Statistical analysis}

Statistical significance was tested by chi square test and Student t-test. p-value of $<0.05$ was considered significant.

\section{RESULTS}

The age group of (44-70 years) were included in this study and mean ages of the women in the positive and negative groups being 55 years and 58.3 years respectively.

Table 1: Symptoms of the patients presented to the OPD.

\begin{tabular}{|ll|}
\hline Symptoms & Total cases $(\mathbf{n}=\mathbf{3 0})$ \\
\hline Postmenopausal bleeding & $15(50 \%)$ \\
\hline Abnormal vaginal discharge & $4(13 \%)$ \\
\hline Post coital bleeding & $2(6 \%)$ \\
\hline Unhealthy looking cervix & $9(23.3 \%)$ \\
\hline
\end{tabular}

Table 2: Swede's score.

\begin{tabular}{|c|c|c|c|}
\hline Characteristics & $\mathbf{0}$ & 1 & 2 \\
\hline Aceto uptake & Zero or transparent & Shady, milky (not transparent /opaque & Distinct, opaque white \\
\hline Margins/surface & Diffuse & $\begin{array}{l}\text { Sharp but irregular, geographical } \\
\text { satellites }\end{array}$ & $\begin{array}{l}\text { Sharp and even, difference in } \\
\text { surface level, including "cuffing" }\end{array}$ \\
\hline Vessels & Fine, regular & Absent & Coarse, atypical \\
\hline Lesion size & $<5 \mathrm{~mm}$ & $5-15 \mathrm{~mm}$ or 2 quadrants & $\begin{array}{l}>15 \mathrm{~mm} \text { or } 3-4 \text { quadrants/ } \\
\text { endocervically undefined }\end{array}$ \\
\hline Iodine staining & Brown & Faintly or patchy yellow & Distinct yellow \\
\hline
\end{tabular}

0-3 low grade, 4-6 high grade (non-invasive), 7-10 high grade suspected invasive.

Table 3: Final diagnosis of the study.

\begin{tabular}{|ll|}
\hline Diagnosis & Total cases $(\mathbf{n}=\mathbf{3 0})$ \\
\hline Positive cases & 9 \\
\hline High grade CIN & 1 \\
\hline SCC of cervix & 1 \\
\hline Adenocarcinoma & 6 \\
\hline Invasive cancer & 1 \\
\hline Negative cases & 21 \\
\hline Erosion (decubitus ulcer) & 2 \\
\hline Tubercular & 1 \\
\hline Endocervical mucus polp & 4 \\
\hline Cervical fibroid & 2 \\
\hline $\begin{array}{l}\text { Cervicitis due to atrophy } \\
\text { (no biopsy) }\end{array}$ & 12 \\
\hline
\end{tabular}

Maximum number of patients presented to gynae OPD had complaints of postmenopausal bleeding 15 (50\%), 4 (13\%) patient with abnormal vaginal discharge, $2(6 \%)$ patient with post coital bleeding and 9 (23.3\%) patient with complaint of pelvic pain and on per speculum examination unhealthy looking cervix (Table 1).

Colposcopy was done and scoring was done on the bases of swede's score. On the basis of Swede's score, two groups were formed, Group A with Swede's score less than 4 and another Group B with score 4 or more than that. In Group A there were 12 patients and in Group B there were 18 patients. Group B patients were subjected to colposcopy directed biopsy. Among 18 patients of Group B, 9 patients were positive for malignancy and remaining 9 were false positive (Table 2).

In Group A, 12 patients whose swede score less than 4, there findings were more suggestive of cervicitis due to atrophy, there were given oral estrogen for 7-14 days and repeat colposcopy was done and atrophic changes were seen and symptomatically relieved (Figure 1), (Table 3).

Colposcopy findings were scored and graded according to swede's score and correlation between colposcopic 
impression using RCI and histopathology was highly significant $(\mathrm{p}<0.001)$. Biopsy was done in 18 cases, which were having swede's score of 4 or more than that. Out of 18 cases, 9 cases were positive for malignancy on biopsy but rest 9 cases were negative for malignancy on biopsy. Among 30 cases, 12 cases were graded as low score on swede's index in which biopsy was not done and these patients were symptomatically treated and follow up was done and they were relieved of their symptoms. In false positive cases 5 patients presented with complaint of postmenopausal bleeding and on per speculum examination, cervix was unhealthy looking with bleeding and a small ulcerated region, colposcopy diagnosis of score 6 was made and biopsy was taken, but which was suggestive of cervicitis with ulceration and 4 patients with false positive cases was presented with complain of pain abdomen and foul smelling discharge, colposcopic diagnosis was high grade CIN due to the presence of atypical vessels (misdiagnosed prominent stromal capillaries) and coarse punctations (misdiagnosed subepithelial hemorrhage), and biopsy was negative for any malignant tissue.

Table 4: Procedural problems of colposcopy in the study.

\begin{tabular}{|c|c|c|c|c|}
\hline Procedural problems of colposcopy in the study & Total & Positive & Negative & p value \\
\hline Difficulty in introducing speculum due to atrophy of introitus & $4(13 \%)$ & 2 & 2 & 0.00 \\
\hline \multicolumn{5}{|l|}{ Difficulty in visualizing cervix/ vault due to } \\
\hline Cervix flushed with vaginal vault & $5(17 \%)$ & 3 & 2 & $<0.001$ \\
\hline Relaxed vaginal walls & $2(7 \%)$ & 1 & 1 & 0.86 \\
\hline \multicolumn{5}{|l|}{ Difficulty in performing colposcopy due to } \\
\hline Continuous bleeding from cervix & $3(10 \%)$ & 2 & 1 & 0.08 \\
\hline Difficulty in focusing due to cervical descent & $2(7 \%)$ & 1 & 1 & 0.056 \\
\hline
\end{tabular}

Table 5: Corrective measures to overcome problems of colposcopy.

\begin{tabular}{|ll|l|}
\hline Corrective measure & Total (n=30) & p value \\
\hline Use of Sim's speculum and anterior vaginal wall retractor to visualize cervix/vault & $16(53 \%)$ & $<0.0001$ \\
\hline Use of extended lithotomy position to visualize cervix & $3(3 \%)$ & 0.85 \\
\hline Use of 2\% xylocaine jelly to decrease pain & $4(3.3 \%)$ & 0.86 \\
\hline Oral estrogen therapy before review colposcopy & $14(46.6 \%)$ & 0.84 \\
\hline
\end{tabular}

(Estrogen was administered only to those with a Pap smear report excluding preinvasive or invasive cancer; therefore, the two groups were not statistically compared).

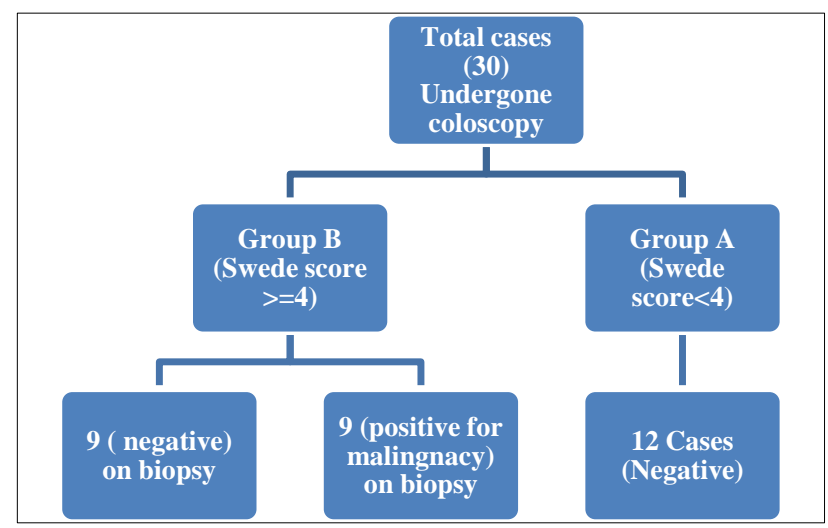

Figure 1: Distribution of cases on the basis of Swede's Score.

Problems associated while visualising the cervix were flushed with vagina, atrophy of introitus, continuous bleeding from the cervix and relaxed vaginal walls (20\%) were significantly more in positive groups. The above changes can be temporarily reversed by short-term administration of oestrogen, use of Sim's speculum and anterior vaginal wall retractor to visualize cervix/vault $p$ $(<0.0001)$, extended lithotomy position to visualize cervix and use of $2 \%$ xylocaine jelly to decrease pain during the procedure were found to be useful (Table 4, 5).

\section{DISCUSSION}

Colposcopy has a central role in the management of premalignant lesions of the cervix, which can be detected by abnormal cytology. It is an essential part of the cervical screening programme. ${ }^{5,6}$ The atrophic changes after menopause cause symptoms mimicking malignancy of the lower genital tract. In postmenopausal women, colposcopic examination typically reveals a pale cervix which is hardly affected by the application of acetic acid. Application of Schiller's iodine results in a pale-yellow staining of the cervix and the vagina, reflecting the lack of glycogen in the postmenopausal squamous epithelium. The squamous epithelium is very thin and insertion of the speculum often results in traumatic hemorrhages, which appear as subepithelial petechiae. The thinned atrophic 
squamous epithelium is easily traumatized and small areas of CIN may be accidentally scrapped off. ${ }^{7}$ The transformation zone is less likely to be visualized in its entirety in postmenopausal women. Crompton reported inversion of the transformation zone into the endocervical canal in approximately $60 \%$ of patients in the over-50 years age group. ${ }^{89}$ Due to the presence of estrogen and progesterone receptors in the cervical epithelium, the latter is sensitive to alterations in estrogen and progesterone levels. Oestrogen, either endogenous or exogenous, increases the cervical volume by causing hypertrophy of the fibromuscular stroma, edema and vascularity these changes result in eversion of the transformation zone. ${ }^{10,11}$

In this study $9(30 \%)$ had a significant lesion and cervical cancer was diagnosed in $66 \%$ of cases. Toplis et al reported significant lesions in $92(86 \%)$ of 107 postmenopausal women referred for colposcopy, $16 \%$ had invasive cancer. The rate of unsatisfactory colposcopy in this study was $30 \%$. Toplis et al and Urcuyo et al reported unsatisfactory colposcopy rate of $53 \%$ in postmenopausal women. ${ }^{5}$ In this study Sim's speculum with anterior vaginal wall retractor and the extended lithotomy position were used for satisfactory visualization of the cervix. Insertion of the speculum is painful due to the atrophic changes, thus use of sterile normal saline to wet the specula and other vaginal instruments found helpful in reducing the pain. In my study use of oral estrogen therapy proved to be a valuable adjunct in patients with initial diagnostic difficulty, and averted unnecessary biopsy. The accuracy of colposcopy in this study was $70 \%$ while $84 \%$ reported by Toplis et al. This means colposcopy a non-invasive procedure, if done which proper technique especially in post-menopausal women, then authors can reduce the burden of doing biopsies in benign cases. Use of corrective methods to overcome the problems related to visualizations and procedural difficulties, then colposcopy can be used as screening tool in post-menopausal specially in low resource settings. ${ }^{12}$ Combining histopathology of the tissue along with colposcopy in high risk cases, cases with unsatisfactory colposcopy finding will reduce the chance of missing malignant lesions. ${ }^{13}$

\section{CONCLUSION}

Colposcopy in postmenopausal women is challenging due to the atrophic changes in the genital tract. Thus, procedure should be performed by experienced colposcopist with proper technique to improve the accuracy of the procedure.

Funding: No funding sources Conflict of interest: None declared

Ethical approval: The study was approved by the Institutional Ethics Committee

\section{REFERENCES}

1. National Cancer Registry Programme. Indian Council of Medical Research. Consolidated report of the population-based cancer registries.1990-1996. Bangalore: Coordinating Unit, NCRP (ICMR). 2001:9-75.

2. Registrar General and Census Commissioner, India. 2001 Census of India. Available at: http://www.censusindia.net/pca_main.html. Accessed on $24^{\text {th }}$ July 2019.

3. Burke L, Antonioli DA, Ducatman BS. Colposcopy: Text and Atlas. Norwalk. Appleton and Lange; 1991.

4. Baliga BS. Principles and Practice of Colposcopy. New York: McGraw Hill Medical Publications; 2004.

5. Toplis PJ, Casemore V, Hallam N. Evaluation of colposcopy in the postmenopausal woman. $\mathrm{Br} \mathbf{J}$ Obstet Gynaecol. 1986;93:843-51.

6. Department of Health. National cervical Screening programme. HSG (93) 41. London; 1993.

7. Crompton AC. The cervical epithelium during the menopause In: Jordan J, Singer A, editors; 1976:33.

8. Saunders N, Anderson D, Gilbert L, Sharp F. Unsatisfactory colposcopy and the response to orally administered oestrogen: a randomized double-blind placebo-controlled trial. Inte J Obstet Gynaecol. 1990;97(8):731-3.

9. Mossa MA, Carter PG, Barton DP, Young MP. Cervical intraepithelial neoplasia in postmenopausal women: difficulties in cytology, colposcopy and treatment. The Obstet Gynaecol. 2001;3(1):8-12.

10. Jammalamadaka A, Manjula J, Shakuntala BB. Problems and pitfalls of colposcopy in postmenopausal women. J Obstet Gynecol India. 2007;57:525-9.

11. Galhardo CL, Soares JM, Simoes RS, Haidar MA, Rodrigues de Lima G, Baracat EC. Estrogen effects on the vaginal $\mathrm{pH}$, flora, and cytology in late postmenopause after a long period without hormone therapy. Clin Exp Obstet Gynecol. 2006;33:85-9.

12. Sellors JW, Sankaranarayanan MDR. Colposcopy and treatment of cervical intraepithelial neoplasia: a beginners' manual. Available at: http://www.iarc.fr/.Accessed.2003. Accessed on $24^{\text {th }}$ July 2019.

13. Woodman CB, Jordan JA. Colposcopy services in the West Midlands region. Br Med J. 1989;299:899.

Cite this article as: Kaur A, Singh G. Colposcopy in postmenopausal women: a challenging procedure. Int J Reprod Contracept Obstet Gynecol 2020;9:3341-4. 